\title{
In Vitro Evaluation of Physical and Mechanical Properties of Light-Curing Resin Cement: A Comparative Study
}

\author{
Luís Felipe Espíndola-Castro ${ }^{1}$ Oscar Felipe Fonseca de Brito ${ }^{1} \quad$ Larissa Gabrielle Assis Araújo $^{1}$ \\ Izabella Luiza Aragão Santos ${ }^{1}$ Gabriela Queiroz De Melo Monteiro ${ }^{1}$
}

1Dental School, Faculdade de Odontologia de Pernambuco, Universidade de Pernambuco (FOP/UPE), Camaragibe, Brazil

\begin{abstract}
Address for correspondence Luís Felipe Espíndola-Castro, DDS, MSc, Dental School, Universidade de Pernambuco, Av. General Newton Cavalcanti, 1650, Camaragibe, Brazil (e-mail: lipe_espindola@hotmail.com).
\end{abstract}

Eur J Dent 2020;14:152-156

\begin{abstract}
Keywords

- dental cement

- hardness

- sorption

- solubility

- color

Objective The aim of study was to evaluate in vitro the surface hardness, sorption, solubility, and color stability of three light-cured resin cements, namely RelyX Veneer (RLX), Variolink Veneer (VLK), and All Cem Veneer (ACV).

Materials and Methods Cylindrical samples $(15 \times 1 \mathrm{~mm})$ were made for each group using a metallic mold $(n=10)$. Vickers microhardness test was performed, and average hardness was calculated from three indentations (300 gf/15s) per sample. The sorption and solubility of the materials were evaluated according to ISO 4049:2009 based on three samples weighing: initial $\left(m_{1}\right)$, after immersion in distilled water for 7 days $\left(m_{2}\right)$, and final (after removal of all moisture $\left.\left[m_{3}\right]\right)$. The color change was observed using a digital spectrophotometer, at three different time points, baseline, 1 day, and 1 week of immersion in coffee and distilled water (control).

Statistical Analysis Shapiro-Wilk test was used to analyze the normality of the data, and groups were compared using Kruskal-Wallis and Mann-Whitney tests. A significance level of $5 \%$ was used.

Results RLX showed the highest microhardness mean values (36.96 VHN), but higher sorption $\left(23.2 \mu \mathrm{g} / \mathrm{mm}^{3}\right)$ and solubility $\left(2.40 \mu \mathrm{g} / \mathrm{mm}^{3}\right)$, with statistically significant differences with the other groups. For color stability, higher $\Delta \mathrm{E}$ was observed for the samples immersed in coffee $(p=0.009)$. The VLK resin cement presented statistically significant differences from the other groups, with higher color changes in coffee at 1 day (15.14) and after 1 week (23.65).

Conclusion RLX resin cement showed better hardness results. All materials tested performed satisfactorily for sorption and solubility according to ISO 4049:2009. All materials showed high-staining values after 1 week of immersion in coffee.
\end{abstract}

\section{Introduction}

The growth of aesthetic procedures in restorative dentistry has increased the use of ceramic materials for different clinical situations. ${ }^{1,2}$ Establishing a durable bond between tooth tissue, resin cement, and the ceramic substrate is critical to the clinical success and longevity of indirect restorations. ${ }^{3} \mathrm{An}$ important aspect to consider is that the resin cement film around the margins of the restorations is often located close to the free gingival margin or gingival sulcus, ${ }^{4-6}$ a susceptible area of sorption, hydrolysis, and dynamic fatigue which may lead to polymer degradation. ${ }^{7}$

Resin-based luting cement is methacrylate monomers with small filler contents and a photoinitiator. ${ }^{5,6}$ In general, dental polymers' networks are not chemically stable and water impermeable. These monomers have been shown
DOI https://doi.org/ 10.1055/s-0040-1705075 ISSN 1305-7456.
(C2020 Dental Investigation Society
License terms

(1) (1) $\Theta \circledast$ 
to absorb moisture, which is a critical property due to the adverse effects on hydrolytic stability. ${ }^{8}$ This phenomenon may result in material discoloration, mechanical deterioration, degradation of filler-matrix interface, polymer swelling, weakening of the polymer network, 7,8 and stress-induced degradation of the resin cement leading to debonding or fracture of the ceramic restoration. ${ }^{5,8}$

Many factors can influence the coefficient of water diffusion between the polymer network, including filler content and the resin matrix volume. ${ }^{8-10}$ Resin cement with a higher percentage of filler content has lower water sorption and solubility. ${ }^{8}$ Although inherent to polymer materials, sorption and solubility can influence the biocompatibility, mechanical properties, and color stability of resin cements. ${ }^{11}$

The major advantages of light-cured resin cement are color stability, and the working time when compared with dual-cure and chemically activated systems. The staining of resin cement may be caused by intrinsic (filler content, material composition, or type of activation) and extrinsic factors (sorption of media, stains caused by beverages, and food components). ${ }^{12}$ Resin materials composed with smaller fillers showed improved color stability and gloss retention. ${ }^{13}$ Additionally, from a clinical perspective, light-cured resin cements with a lower concentration of tertiary amine display greater long-term color stability. ${ }^{4}$ The extrinsic factors seem to be modulated by the conversion ratio and the physicochemical characteristics of the resin-based materials such as surface roughness and water sorption. ${ }^{14}$

The performance of resin cement on the luting procedure and their mechanical properties are important factors to consider for the clinical success of indirect restorations. ${ }^{6,15}$ Therefore, this study aimed to assess the surface hardness, sorption, solubility, and color stability of light-cured resin cement. The null hypotheses tested were: (1) no difference in microhardness between the evaluated resin cement, (2) no difference in the sorption and solubility between the resin cements tested, and (3) no difference in color stability would be observed between the tested materials.

\section{Materials and Methods}

\section{Preparation of Samples}

The sample size used in the present study followed the recommendations of ISO 4049:2009. ${ }^{16}$ Three commercially available light-cured resin cements were studied ( - Table $\mathbf{1}$ ). Disc-shaped samples of each resin cement were built up by filling a split metal mold ( $15 \mathrm{~mm}$ in diameter $\times 1 \mathrm{~mm}$ thick). ${ }^{16}$

The mold was filled to excess, and the surface of the sample was covered with a mylar matrix strip and microscope glass slab placed on the top. Slight digital compression was applied to the glass for 20 seconds to avoid porosities and minimize possible voids due to entrapped air on the uncured material inside the mold. The polymerization of all the samples was performed with a light-emitting diode source (Radii-Cal, Dental Product SDI, Bayswater, Vitoria, Australia) for 40 seconds on each sample side with $1,200 \mathrm{~mW} / \mathrm{cm}^{2}$ irradiance.
Table 1 Composition of the studied resin cements

\begin{tabular}{|l|l|l|}
\hline $\begin{array}{l}\text { Resin } \\
\text { cement }\end{array}$ & Composition & $\begin{array}{l}\text { Manufacturer } \\
\text { batch number }\end{array}$ \\
\hline $\begin{array}{l}\text { RelyX } \\
\text { Veneer }\end{array}$ & $\begin{array}{l}\text { Silane-treated ceramics, } \\
2,2^{\prime} \text {-ethylenedioxyethyl } \\
\text { dimethacrylate, bisphenol } \\
\text { A diglycidyl ether dimeth- } \\
\text { acrylate, silane-treated silica, } \\
\text { functionalized dimethacrylate } \\
\text { polymer and water }\end{array}$ & $\begin{array}{l}3 \mathrm{M} / \mathrm{ESPE} \\
1814900518\end{array}$ \\
\hline $\begin{array}{l}\text { Variolink } \\
\text { Veneer }\end{array}$ & $\begin{array}{l}\text { Urethane dimethacrylate and } \\
\text { other methacrylate mono- } \\
\text { mers. Ytterbium trifluoride } \\
\text { and spheroidal mixed oxides }\end{array}$ & Ivoclar Vivadent \\
X08164 \\
\hline All Cem & $\begin{array}{l}\text { Methacrylic monomers, } \\
\text { Veneer } \\
\text { camphorquinone, coinitiators, } \\
\text { stabilizers, pigments, silanized } \\
\text { Barium Aluminum Silicate glass } \\
\text { particles and silicon dioxide }\end{array}$ & FGM 120118 \\
\hline
\end{tabular}

a3M/ESPE: St. Paul, MN, United States; Ivoclar Vivadent: Schaan, Liechtenstein; FGM: Santa Catarina, Brazil.

The sample was removed from the metal mold, and the excess flash was detached using silicon carbide papers of decrescent grit (nos. 600, 1,000, and 1,500). The dimensions of each sample were confirmed using a digital caliper ( $\pm 0.01 \mathrm{~mm}$; MDC-25 M, Mitutoyo, Tokyo, Japan). The samples were then washed in an ultrasonic cleaner (Cristófoli, Paraná, Brazil) with distilled water for 10 minutes and gently air dried.

\section{Hardness Vickers Number Test}

The hardness test was conducted using a digital microhardness tester (ISH-MR150/INSIZE, São Paulo, Brazil) under a 300 -gf load for 15 seconds $(n=10)$. Three indentations were done in each sample and the mean HVN was then calculated.

\section{Sorption and Solubility}

The evaluation of sorption and solubility followed previous studies. ${ }^{4,59,11}$ Following the hardness test, five samples of each resin cement were selected and placed in a desiccator containing freshly dried silica gel at $37 \pm 2^{\circ} \mathrm{C}$. After a 24-hour period, the samples were maintained at $23 \pm 2^{\circ} \mathrm{C}$ for 2 hours. All the samples were weighed on an analytical balance (0.01 mg; AUW 220D, Shimadzu Analytical Balance, Tokyo, Japan).

$$
\mathrm{S}_{\mathrm{p}}=\frac{\left(m_{2}-m_{1}\right)}{\mathrm{V}} \quad \mathrm{S}_{\mathrm{L}}=\frac{\left(m_{1}-m_{3}\right)}{\mathrm{V}}
$$

The samples were repeatedly weighed until a constant mass $(m 1)$ was attained. The diameter and thickness of each sample were measured with the digital caliper at four points. The mean values were used to calculate the volume of the samples $(V)$ in $\mathrm{mm}^{3}$. The samples were then stored in plastic vials containing distilled water and kept at $37^{\circ} \mathrm{C}$ for 7 days. Samples were carefully blotted dried with absorbent paper, 
weighed, and the recorded mass was registered ( $m 2)$. The samples were placed in a desiccator and constantly weighed (daily) until a consistent mass with variation less than $0.1 \mathrm{mg}$ (m3) was attained. The sorption and the solubility were calculated using the following equations: $4,5,9$

\section{Color Stability Evaluation}

The color analysis was based on Shiozawa et al (2015) ${ }^{14}$ using the CIELAB color space and a digital spectrophotometer (Vita Easy Shade; Wilcos, Rio de Janeiro, Brazil). Measurements were performed at three different times: (1) before immersion (baseline), (2) after 1 day, and (3) after 1 week of storage in distilled water and coffee. The coffee solution was prepared by dissolving $0.51 \mathrm{~g}$ of instant coffee powder in $50 \mathrm{~mL}$ of distilled water (Nescafé, Nestle, São Paulo, SP, Brazil). The same samples used for the hardness test were used for the evaluation of the color stability after immersion in coffee. The remaining samples, used for sorption and solubility tests, were used as the control group (immersion in distilled water).

The CIELAB system is composed of three axes: $L^{*}$ (lightness from $0=$ black up to $100=$ white), $a^{*}$ (from $a=$ green up to $+a=$ red), and $b^{*}$ (from $b=$ blue up to $+b=$ yellow). The following equation calculated the color change $(\Delta E)^{12,14}$ :

$$
\Delta E=\left[\left(L^{*}{ }_{1}-L^{*}{ }_{2}\right)^{2}+\left(a^{*}{ }_{1}-a^{*}{ }^{*}\right)^{2}+\left(b^{*}{ }_{1}-b^{*}{ }_{2}\right)^{2}\right]^{1 / 2}
$$

A higher $\Delta E$ value also means a greater color change for each sample. An $\Delta E \leq 1$ shows a color change undetectable for human eyes. The discoloration is perceptible but clinically accepted when the mean is between 1 and $3.3(1<\Delta E<3.3)$. For means over $3.3(\Delta E>3.3)$, the alteration is detected by human eyes and clinically unaccepted. ${ }^{17}$
For the evaluation, samples were positioned over a brown paper as a standard backing. Two readings in the central area of each sample were done, and the means were considered for analysis.

\section{Statistical Analysis}

Data were analyzed using Statistical Package for the Social Science version 18 (SPSS; Chicago, Illinois, United States). The Shapiro-Wilk's test evaluated the presence of normal distributions. The Mann-Whitney and Kruskal-Wallis's tests were applied whenever differences were observed between groups. For all tests, a $p<0.05$ was considered statistically significant.

\section{Results}

The microhardness results are shown in - Table 2 . The resin cement RLX showed the highest mean values (36.96 VHN) with statistically significant differences with the other groups ACV (27.40) and VLK (23.23).

Differences between sorption $(p=0.003)$ and solubility $(p=0.006)$ were also observed within materials ( - Table 2$)$. The RLX group showed higher sorption $\left(23.2 \mu \mathrm{g} / \mathrm{mm}^{3}\right)$ and solubility $\left(2.40 \mu \mathrm{g} / \mathrm{mm}^{3}\right)$.

For color stability ( - Table 3 ), the mean $\Delta E$ showed a significant difference between water and coffee immersion for all tested resin cement in both moments of evaluation ( $p=0.009$ ), with higher $\Delta E$ for the samples immersed in coffee. The VLK resin cement presented statistically significant differences from the other groups, with higher color changes in coffee at 1 day (15.14) and after 1 week (23.65).

Table 2 Mean and standard deviation of Vickers hardness, sorption, and solubility of the studied resin cements

\begin{tabular}{|l|l|l|l|}
\hline Resin cement & VHN & Sorption & Solubility \\
\hline RLX & $36.96(1.15)^{\mathrm{A}}$ & $23.2(1.3)^{\mathrm{A}}$ & $2.40(0.17)^{\mathrm{A}}$ \\
\hline ACV & $27.40(0.88)^{\mathrm{B}}$ & $12.4(2.5)^{\mathrm{B}}$ & $0.14(0.05)^{\mathrm{B}}$ \\
\hline VLK & $23.23(0.73)^{\mathrm{B}}$ & $18.1(2.5)^{\mathrm{C}}$ & $0.20(0.10)^{\mathrm{B}}$ \\
\hline$p$-value & $<0.001$ & 0.003 & 0.006 \\
\hline
\end{tabular}

Abbreviations: ACV, All Cem Veneer; RLX, RelyX Veneer; VHN, hardness vickers number; VLK, Variolink Veneer.

Note: Different superscript letters indicate statistical differences through Mann-Whitney test.

"Kruskal-Wallis test.

Table 3 Mean and standard deviation of the color stability for each immersion media and studied resin cement

\begin{tabular}{|c|c|c|c|c|c|c|}
\hline \multirow{2}{*}{$\begin{array}{l}\text { Resin } \\
\text { cement } \\
\text { type }\end{array}$} & \multicolumn{2}{|l|}{$\Delta E_{1 \text { day }}$} & \multirow[t]{2}{*}{$p$-value ${ }^{\mathrm{D}}$} & \multicolumn{2}{|l|}{$\Delta E_{1 \text { week }}$} & \multirow[t]{2}{*}{$p$-value* } \\
\hline & Water & Coffee & & Water & Coffee & \\
\hline RLX & $1.69 \pm 0.23^{\mathrm{a}, \mathrm{A}}$ & $7.96 \pm 0.22^{\mathrm{a}, \mathrm{B}}$ & 0.009 & $2.70 \pm 0.15^{\mathrm{a}, \mathrm{A}}$ & $14.50 \pm 0.62^{\mathrm{a}, \mathrm{c}}$ & 0.009 \\
\hline $\mathrm{ACV}$ & $1.62 \pm 0.32^{\mathrm{a}, \mathrm{A}}$ & $9.07 \pm 0.38^{\mathrm{a}, \mathrm{B}}$ & 0.009 & $2.64 \pm 0.35^{\mathrm{a}, \mathrm{A}}$ & $12.46 \pm 0.44^{\mathrm{a}, \mathrm{B}}$ & 0.009 \\
\hline VLK & $1.00 \pm 0.13^{\mathrm{b}, \mathrm{A}}$ & $15.14 \pm 0.50^{\mathrm{b}, \mathrm{B}}$ & 0.009 & $2.36 \pm 0.33^{\mathrm{a}, \mathrm{A}}$ & $23.65 \pm 1.10^{\mathrm{b}, \mathrm{c}}$ & 0.009 \\
\hline$p$-value ${ }^{\#}$ & 0.013 & 0.002 & & 0.254 & 0.002 & \\
\hline
\end{tabular}

Abbreviations: ACV, All Cem Veneer; RLX, RelyX Veneer; VLK, Variolink Veneer.

Note: Different superscript letters indicate statistical differences through Mann-Whitney test. Lowercase letters indicate differences between groups (column) and uppercase letters indicate differences between evaluation periods for each immersion media (rows).

"Mann-Whitney test

\#Kruskal-Wallis test. 


\section{Discussion}

The physical and mechanical properties investigated were different among the tested light-curing resin cement. In the present study, all three tested null hypotheses were rejected. The results could be attributed to the different chemical composition of the materials, especially their organic matrices. ${ }^{11}$

Surface hardness is defined as resistance to permanent indentation or penetration of the material surface. This assessment is intuitively related to the wear of dental materials in the oral environment. ${ }^{18}$ The Rely-X Veneer resin cement showed higher VHN with statistically significant differences from the other materials. The materials higher degree of conversion could influence the materials VHN results. For resin cement, the percentage of conversion is around $60 \%$, and incomplete material polymerization results in higher sorption and solubility values inducing faster resin cement degradation. ${ }^{6} 19$ For Demarco et al (2012), ${ }^{20}$ resin materials with UDMA/TEGDMA-based formulation showed significantly higher wear resistance. However, the resin cement that presented the highest hardness value in the present study has Bis-GMA monomers in its composition.

The distilled water is a solvent recommended by the International Organization for Standardization of polymer-based materials. ${ }^{16}$ In the present study, we used this substance as a control medium for the experimental phases.

Depending on the limit of the cavity preparation (supragingivally), resin cement may still suffer mechanical brushing action. It is common for the clinician to worry about how these materials behave in different situations. ${ }^{9}$ However, in the study by Nayyer et al (2018), ${ }^{21}$ in which the hardness of resinous compounds was evaluated after simulated brushing cycles, the authors concluded that brushing was not able to compromise the hardness of the materials.

Different beverages are used to test color stability such as coffee, ${ }^{14,22}$ black tea, ${ }^{22,23}$ cola, $^{22,24}$ and red wine ${ }^{22,23}$, which are usual drinks in a daily diet with a high potential to stain resin-based materials. Previous studies have shown that the color change is more significant in coffee, black tea, and red wine when compared with cola beverages. ${ }^{24-26}$ Water can be absorbed in the resin matrix, causing expansion, and plasticizing the resin. The matrix content and bond strength of the resin matrix-inorganic filler interface have a more substantial influence on the degree of water sorption, which may create microcracks where the beverage stain can penetrate cause discoloration on the cement surface. ${ }^{14}$

In analyzing color stability, there is a difference between the color perceptibility and acceptability. A perceptibility of color difference value $(\Delta E)$ of 3.7 is acceptable for dental composite veneer restorations and tooth substance. ${ }^{27}$ In the present study, independently of the immersion time, all the resin cement immersed in the water had an $\Delta E$ smaller than the previously reported acceptable threshold. When the samples were immersed in coffee, regardless of the immersion time, the color differences were higher than the reported acceptable threshold.
All samples were polymerized by the same LED light source at its maximum power. The pigmentation of the samples can be influenced by the type of light-curing device used. Zafa et $\mathrm{a}^{28}$ evaluated the influence of light-curing units (Quartz Tungsten Halogen [QTH] and light emitting diode [LED]) on the pigmentation of resin composites. The authors observed that the materials polymerized with LED showed significant color stability when compared with QTH.

Even after polymerization, resin materials are not stable, ${ }^{9}$ and various components such as unreacted monomers are released from resinous materials during the first 7 days of immersion in distilled water. ${ }^{29}$ Moreover, the saturation period reached for resinous materials may vary within 7 to 60 days. ${ }^{30}$ Many studies have reported the influence of different substances on the integrity of resin materials, ${ }^{6,8,9}$ with the immersion periods and the storage mediums strongly influencing their sorption and solubility. ${ }^{9,13,31}$

The sorption and solubility are a diffusion-controlled phenomenon that occurs directly on the resin matrix ${ }^{11}$ and appears to be related to material composition and concentration, size, and type of fillers. ${ }^{4}$ In the present study, the RLX resin cement had the highest sorption and solubility means $\left(23.2 \mu \mathrm{m} / \mathrm{cm}^{3}\right.$ and $2.40 \mu \mathrm{m} / \mathrm{cm}^{3}$, respectively). High sorption is not necessarily correlated to high solubility $8.31 \mu \mathrm{m} / \mathrm{cm}^{3}$. The water uptake depends on the degree of conversion, monomers mobility, and hydrophilicity., ${ }^{9,13}$

Materials with the presence of electropositive metallic ions on their composition (e.g., barium and zinc) tend to react with water. According to American Dental Association and ISO specifications, the sorption and solubility of each resin material over a storage period of 7 days must be smaller than $40 \mu \mathrm{m} / \mathrm{cm}^{3}$ and $7.5 \mu \mathrm{m} / \mathrm{cm}^{3}$, respectively. In the present study, the sorption values ranged from $12.4 \mu \mathrm{m} / \mathrm{cm}^{3}$ to $23.2 \mu \mathrm{m} / \mathrm{cm}^{3}$, which are accepted by each standard. The solubility values were also under the accepted values, ranging from $0.14 \mu \mathrm{m} / \mathrm{cm}^{3}$ to $2.40 \mu \mathrm{m} / \mathrm{cm}^{3} .3 .21$

The limitations of the present study are related to the difficulty in simulating oral conditions. The in vitro setup simulates extreme conditions, such as immersion of samples for 7 consecutive days in coffee. On the other hand, sorption and solubility testing according to the ISO standards only evaluates the materials for 1 week of immersion in distilled water.

\section{Conclusion}

The light-cured resin cements tested showed good mechanical resistance and showed good results with respect to sorption and solubility according to ISO 4049:2009 recommendations. However, resin cements showed low color stability with coffee immersion after 7 days. The findings suggest that optical properties of these materials could be improved.

\section{Conflict of Interest}

None declared. 


\section{References}

1 Almohareb T, Alkatheeri MS, Vohra F, Alrahlah A. Influence of experimental staining on the color stability of indirect computer-aided design/computer-aided manufacturing dental provisional materials. Eur J Dent 2018;12(2):269-274

2 Blum IR, Nikolinakos N, Lynch CD, Wilson NH, Millar BJ, Jagger DC. An in vitro comparison of four intra-oral ceramic repair systems. J Dent 2012;40(11):906-912

3 Novais VR, Raposo LH, Miranda RR, Lopes CC, Simamoto PC, Soares CJ. Degree of conversion and bond strength of resincements to feldspathic ceramic using different curing modes. J Appl Oral Sci 2017;25(1):61-68

4 Leal CL, Queiroz A, Foxton RM, Argolo S, Mathias P, Cavalcanti AN. Water sorption and solubility of luting agents used under ceramic laminates with different degrees of translucency. Oper Dent 2016;41(5):E141-E148

5 Petropoulou A, Vrochari AD, Hellwig E, Stampf S, Polydorou O. Water sorption and water solubility of self-etching and selfadhesive resin cements. J Prosthet Dent 2015;114(5):674-679

6 Silva EM, Noronha-Filho JD, Amaral CM, Poskus LT, Guimarães JG. Long-term degradation of resin-based cements in substances present in the oral environment: influence of activation mode. J Appl Oral Sci 2013;21(3):271-277

7 Pan Y, Xu X, Sun F, Meng X. Surface morphology and mechanical properties of conventional and self-adhesive resin cements after aqueous aging. J Appl Oral Sci 2018;27(1):e20170449

8 Alshali RZ, Salim NA, Satterthwaite JD, Silikas N. Longterm sorption and solubility of bulk-fill and conventional resin-composites in water and artificial saliva. J Dent 2015;43(12):1511-1518

9 de Brito O, de Oliveira I, Monteiro G. Hydrolytic and biological degradation of bulk-fil and self-adhering resin composite. Oper Dent 2019;44(5):E223-E233

10 Martin N, Jedynakiewicz N. Measurement of water sorption in dental composites. Biomaterials 1998;19(1-3):77-83

11 Marghalani HY. Sorption and solubility characteristics of self-adhesive resin cements. Dent Mater 2012;28(10): e187-e198

12 Ramos NC, Luz JN, Valera MC, Melo RM, Saavedra G, Bresciani E. Color stability of resin cement exposed to aging. Oper Dent 2019;44(6):609-614

13 Salgado VE, Cavalcante LM, Moraes RR, Davis HB, Ferracane JL, Schneider LF. Degradation of optical and surface properties of resin-based composites with distinct nanoparticle sizes but equivalent surface area. J Dent 2017;59(1):48-53

14 Shiozawa M, Takahashi H, Asakawa Y, Iwasaki N. Color stability of adhesive resin cements after immersion in coffee. Clin Oral Investig 2015;19(2):309-317

15 Malchiodi L, Zotti F, Moro T. De Santis D, Albanese M. Clinical and Esthetical Evaluation of 79 Lithium Disilicate Multilayered Anterior Veneers with a Medium Follow-Up of 3 Years. Eur J Dent 2019;13(4):581-588

16 International Organization for Standardization. ISO 4049: Dentistry polymer - based filling, restorative and luting materials. Switzerland, 2009. Available at: https://www.iso. org/standard/42898.html. Accessed February 5, 2020

17 Monteiro, GQM, Oliveira ILM, Brito, OFF, Guedes BP, Amorim MSML, Maia AMA. Chromatic and surface alterations in enamel subjected to brushing with desensitizing whitening toothpaste. Eur J Gen Dent 2016;5(3):115-121

18 Venter SAS, Fávaro AL, Radovanovic E, Girotto EM. Hardness and degree of conversion of dental restorative composites based on an organic-inorganic hybrid. Mater Res 2013;16(4):898-902

19 De Souza G, Braga RR, Cesar PF, Lopes GC. Correlation between clinical performance and degree of conversion of resin cements: a literature review. J Appl Oral Sci 2015;23(4):358-368

20 Demarco FF, Corrêa MB, Cenci MS, Moraes RR, Opdam NJ. Longevity of posterior composite restorations: not only a matter of materials. Dent Mater 2012;28(1):87-101

21 Nayyer M, Zahid S, Hassan SH, et al. Comparative abrasive wear resistance and surface analysis of dental resin-based materials. Eur J Dent 2018;12(1):57-66

22 Arocha MA, Mayoral JR, Lefever D, Mercade M, Basilio J, Roig M. Color stability of siloranes versus methacrylate-based composites after immersion in staining solutions. Clin Oral Investig 2013;17(6):1481-1487

23 Falkensammer F, Arnetzl GV, Wildburger A, Freudenthaler J. Color stability of different composite resin materials. J Prosthet Dent 2013;109(6):378-383

24 Malekipour MR, Sharafi A, Kazemi S, Khazaei S, Shirani F. Comparison of color stability of a composite resin in different color media. Dent Res J (Isfahan) 2012;9(4):441-446

25 Ertaş E, Güler AU, Yücel AC, Köprülü H, Güler E. Color stability of resin composites after immersion in different drinks. Dent Mater J 2006;25(2):371-376

26 Bagheri R, Burrow MF, Tyas M. Influence of food-simulating solutions and surface finish on susceptibility to staining of aesthetic restorative materials. J Dent 2005;33(5):389-398

27 Johnston WM, Kao EC. Assessment of appearance match by visual observation and clinical colorimetry. J Dent Res 1989;68(5):819-822

28 Zafa MS, Khan E, Aversa R, Petrescu RV, Apicella A, Petrescu FI. Influence of curing light type and staining medium on the discoloring stability of dental restorative composite. Am J Biochem Biotechnol 2017;13(1):42-50

29 Ferracane JL, Condon JR. Rate of elution of leachable components from composite. Dent Mater 1990;6(4):282-287

30 Ortengren U, Wellendorf H, Karlsson S, Ruyter IE. Water sorption and solubility of dental composites and identification of monomers released in an aqueous environment. J Oral Rehabil 2001;28(12):1106-1115

31 Zhang Y, Xu J. Effect of immersion in various media on the sorption, solubility, elution of unreacted monomers, and flexural properties of two model dental composite compositions. J Mater Sci Mater Med 2008;19(6):2477-2483 